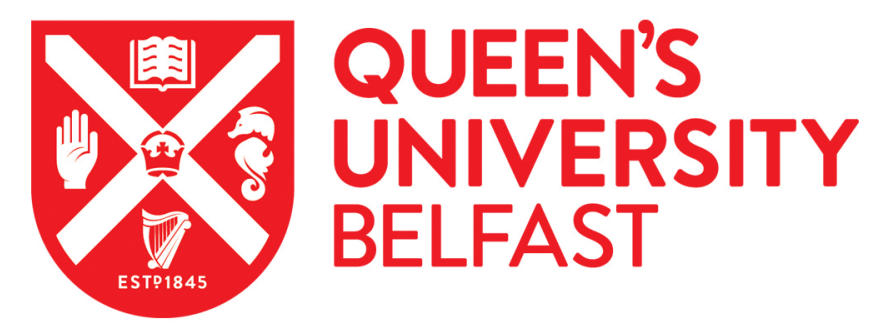

\title{
Role of CFTR, Pseudomonas aeruginosa and Toll-like receptors in cystic fibrosis lung inflammation
}

Buchanan, P. J., Ernst, R. K., Elborn, J., \& Schock, B. (2009). Role of CFTR, Pseudomonas aeruginosa and Toll-like receptors in cystic fibrosis lung inflammation. 863-867. Paper presented at Conference on Biochemical Basic of Respiratory Disease, Loughborough, United Kingdom. https://doi.org/10.1042/BST0370863

Queen's University Belfast - Research Portal:

Link to publication record in Queen's University Belfast Research Portal

\section{General rights}

Copyright for the publications made accessible via the Queen's University Belfast Research Portal is retained by the author(s) and / or other copyright owners and it is a condition of accessing these publications that users recognise and abide by the legal requirements associated with these rights.

Take down policy

The Research Portal is Queen's institutional repository that provides access to Queen's research output. Every effort has been made to ensure that content in the Research Portal does not infringe any person's rights, or applicable UK laws. If you discover content in the Research Portal that you believe breaches copyright or violates any law, please contact openaccess@qub.ac.uk. 


\title{
Role of CFTR, Pseudomonas aeruginosa and Toll-like receptors in cystic fibrosis lung inflammation
}

\author{
Paul J. Buchanan*1, Robert K. Ernst†, J. Stuart Elborn* and Bettina Schock* \\ "School of Medicine, Dentistry and Biomedical Science, Centre for Infection and Immunity, Respiratory Research, Queens University Belfast, \\ Belfast BT12 6BN, U.K., and †Department of Microbial Pathogenesis, University of Maryland Baltimore, Baltimore, MD 21201, U.S.A.
}

\begin{abstract}
CF (cystic fibrosis) is a severe autosomal recessive disease most common in Northwest European populations. Underlying mutations in the CFTR (CF transmembrane conductance regulator) gene cause deregulation of ion transport and subsequent dehydration of the airway surface liquid, producing a viscous mucus layer on the airway surface of CF patients. This layer is readily colonized by bacteria such as Pseudomonas aeruginosa. Owing to the resulting environment and treatment strategies, the bacteria acquire genetic modifications such as antibiotic resistance, biofilm formation, antimicrobial peptide resistance and pro-inflammatory lipid A structures. Lipid $A$ is a component of the lipopolysaccharide cell wall present on bacteria and is recognized by TLR4 (Toll-like receptor 4). Its detection elicits a pro-inflammatory response that is heightened over time due to the addition of fatty acids to the lipid $A$ structure. Eradication of bacteria from the lungs of CF patients becomes increasingly difficult and eventually leads to mortality. In the present review, we describe the role of lipid A as a virulent factor of Ps. aeruginosa; however, it appears that further work is needed to investigate the role of CFTR in the innate immune response and in modifying the pathogen-host interaction.
\end{abstract}

\section{Introduction}

CF (cystic fibrosis; OMIM no. 219700) is a lethal autosomal recessive disease found worldwide, but most commonly in Northwest European populations, where the prevalence is approx. 1 in 2500 newborns [1]. Originally described in 1938 [2], its biochemical basis was later linked to a mutation in the CFTR (CF transmembrane conductance regulator) gene in 1989 [3]. CFTR is a unique protein belonging to the ABC transporter (ATP-binding-cassette transporter) superfamily [3]. Principally, CFTR is expressed apically in exocrine epithelial cells, and functions primarily as a chloride ion $\left(\mathrm{Cl}^{-}\right)$channel [3]. As epithelial cells are found ubiquitously throughout the body, multiple organs can be affected by disease, such as the pancreas [4,5], sweat glands [6], vas deferens [3], adult epididymis [3], gall bladder and the bile duct [7]. However, the main cause of morbidity and mortality in $\mathrm{CF}$ is characteristically associated with respiratory disease, which is a result of persistent pulmonary infection and chronic inflammation $[8,9]$.

\footnotetext{
Key words: cystic fibrosis, inflammation, lipid A, lipopolysaccharide, Pseudomonas aeruginoso Toll-like receptor (TLR)

Abbreviations used: ASL, airway surface liquid; CAMP, cationic antimicrobial peptide; CF, cystic fibrosis; CFTR, CF transmembrane conductance regulator; ENaC, epithelial $\mathrm{Na}^{+}$channel; IL, interleukin; IL-1R, IL-1 receptor; IL-1RI, type I IL-1R; IRAK-4, IL-1R-associated kinase 4; LPS, lipopolysaccharide; MyD88, myeloid differentiation factor 88; NBD, nucleotide-binding domain; $\mathrm{NF}-\kappa \mathrm{B}$, nuclear factor $\kappa \mathrm{B}$; PAMP, pathogen-associated molecular pattern; $\mathrm{PCL}$, periciliary liquic layer; TIR, Toll/IL-1R; TLR, Toll-like receptor; TNF, tumour necrosis factor; TRAF-6, TNF-receptorassociated factor- 6 .

${ }^{1}$ To whom correspondence should be addressed (email pbuchanan03@qub.ac.uk).
}

\section{CFTR}

The underlying molecular basis for the inflammatory lung disease seen in CF patients stems from mutations in the CFTR gene. The gene itself is located on chromosome $7 \mathrm{q} 31.2$ and produces a transcript that is $6.5 \mathrm{~kb}$ in size $[3,10]$. This transcript codes for the CFTR protein, which comprises 1480 amino acids and has a molecular mass of $1.7 \mathrm{kDa}$. The crystal structure showed that the overall protein is composed of five domains: two MSDs (membrane-spanning domains) each consisting of six $\alpha$-helices, two NBDs (nucleotide-binding domains; capable of ATP hydrolysis) and a regulatory domain (target of phosphorylation by protein kinase A) [3,11]. To date, throughout the CFTR gene approx. 1600 mutations have been sequenced (http://www. genet.sickkids.on.ca/cftr/StatisticsPage.html); however, the mutation that accounts for approx. $70 \%$ of $\mathrm{CF}$ chromosomes is $\Delta$ F508 (F508del) [13]. The mutation results in a 3-bp deletion, producing a protein lacking a phenylalanine at position 508 located in the NBD1 [3]. Owing to the loss of this residue the protein formed after translation fails to mature properly and is subsequently tagged for ubiquitination and degradation, resulting in a loss of CFTR at the apical membrane [14].

\section{CFTR mutations}

Owing to the large number of mutations and the variation in translation and $\mathrm{Cl}^{-}$channel function, CFTR mutations have been split into five different classes $[15,16]$. Class I mutations are generally deletions, nonsense or frame shifts that result in 
premature truncated proteins. Class II mutants such as $\Delta \mathrm{F} 508$ result in a protein that is defective in protein processing and trafficking. Class III mutants code for a protein that is capable of reaching the apical membrane, but cannot be activated with ATP or cAMP. Both are considered to be the mechanism for channel activation. The result is a protein with little or no ion channel activity. Class IV mutants result in a CFTR that has defective chloride ion channel transport and, finally, class $\mathrm{V}$ mutants are affected by mutations in promoter and splicing regions. Thus, as a result, a fully functional CFTR protein is produced but its presence on the membrane is reduced. Genotype-phenotype studies have shown that mutations within classes I, II and III are associated with increased severity of pulmonary disease, due to the almost total lack of functional CFTR on the apical cell membrane $[15,16]$. Further studies have highlighted class I mutations as the most dominant cause of morbidity and mortality $[17,18]$.

\section{ASL (airway surface liquid)}

It is apparent that mutations in the CFTR cause little or no $\mathrm{Cl}^{-}$channel transport, but how does this affect the lungs of CF patients and bring about the characteristic proinflammatory lung disease? Normally the airway surface is covered with a thin liquid film called the ASL [19], which consists of the PCL (periciliary liquid layer), which is in direct contact with epithelial cells and the upper mucus layer. Together they play a critical role in effective mucociliary and cough clearance of the airway [19]. The PCL extends and maintains the beating of the cilia, as well as providing a low viscous environment to lubricate and separate the mucus layer from the epithelial cell surface. This prevents mucus adhesion and the formation of mucus plugs [19-22]. Finally, the mucus layer on top of the PCL is involved in trapping and removing inhaled pathogens without triggering a substantial innate immune response.

In order for the ASL to effectively assist removal of bacteria by mucociliary clearance, it is important that it remains hydrated and retains a height of approx. $7 \mu \mathrm{m}$ [21]. The ASL height and composition are maintained by two opposing active ion transport channels, namely CFTR and ENaC (epithelial $\mathrm{Na}^{+}$channel) [23]. CFTR is involved in the secretion of $\mathrm{Cl}^{-}$into the ASL and the inhibition of $\mathrm{ENaC}$ to prevent $\mathrm{Na}^{+}$absorption into epithelial cells [19]. As epithelial cells are highly water-permeable, water is drawn out of the cells via osmosis on to the iso-osmotic ASL [24] (Figure 1A). CFTR mutations result in reduced levels of CFTR on the epithelial membrane, $\mathrm{Cl}^{-}$can no longer be secreted on to the airways and regulation of $\mathrm{Na}^{+}$absorption through $\mathrm{ENaC}$ is diminished. As a consequence of this, increased amounts of $\mathrm{Na}^{+}$are absorbed into the cell, with $\mathrm{Cl}^{-}$ following through the paracellular pathway. Subsequently water is drawn from the ASL into the cells (Figure 1B). This depletion of water from the ASL results in (i) increased mucus concentration, (ii) flattening of the cilia, and (iii) adhesion of the mucus layer to the airway surface [21]. The environment produced as a consequence is rich in thick sticky mucus and provides the perfect milieu for colonization and
Figure 1 Role of CFTR in regulating the ASL in healthy individuals (upper panel) and CF patients (lower panel)

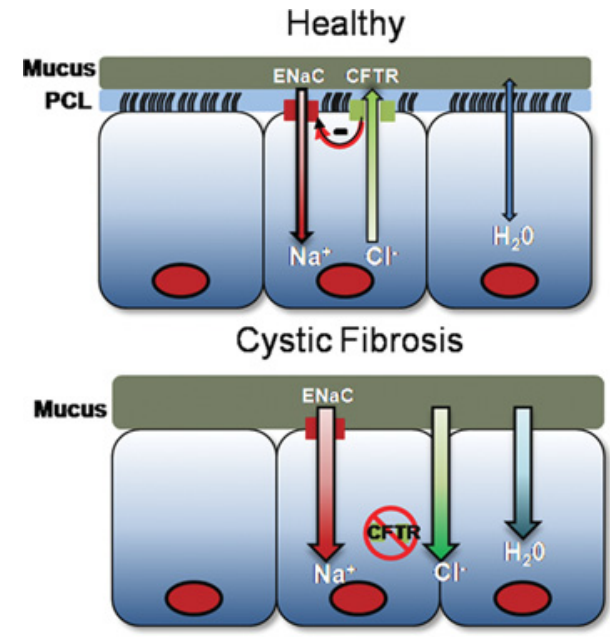

propagation of bacteria such as Pseudomonas aeruginosa and Staphylococcus aureus.

\section{TLRs (Toll-like receptors)}

The adhesion of mucus to the epithelium surface brings epithelial cells into the first line of host defence against colonizing bacteria [25]. Invading bacteria display PAMPs (pathogen-associated molecular patterns), which are recognized by TLRs on the airway epithelium and their activation results in a pro-inflammatory response [26,27]. In 1991 TLRs were initially identified in the fruitfly Drosophila melanogaster as a key receptor in fungal defence [28]. Later that year, it was found that the receptor shared structural homology with an important receptor in mammalian innate immunity, the IL-1RI [type I IL (interleukin)-1 receptor] [29]. To date, 12 mammalian TLRs have been identified, and all of them are postulated or have proved to play a significant role in innate immune responses [30-32]. TLRs are type I transmembrane glycoproteins, which possess a characteristic horseshoe-like extracellular domain composed of LRR (leucine-rich repeat) motifs [30]. Its cytoplasmic signalling domain is composed of 150-200 conserved residues that share homology with IL-1RI; hence it is named the TIR (Toll/IL-1R) domain [33]. The TIR domain plays a key role in recruiting those adaptor proteins containing a TIR domain, which subsequently leads to activation of downstream signalling cascades such as $\mathrm{NF}-\kappa \mathrm{B}$ (nuclear factor $\kappa \mathrm{B}$ ) and production of pro-inflammatory cytokines and chemokines that are abundantly found in the airways of CF patients.

Each TLR has the ability to recognize and discriminate a specific PAMP present on invading pathogens. Together the TLR family is able to respond to a diverse array of species including bacteria, viruses, mycoplasma, yeasts and protozoa. For example, TLRs 3, 7, 8 and 9 recognize pathogen nucleic acids such as viral dsRNA (double-stranded RNA), ssRNA 
Figure 2 General signalling pathway of TLR4 resulting in the release of pro-inflammatory mediators

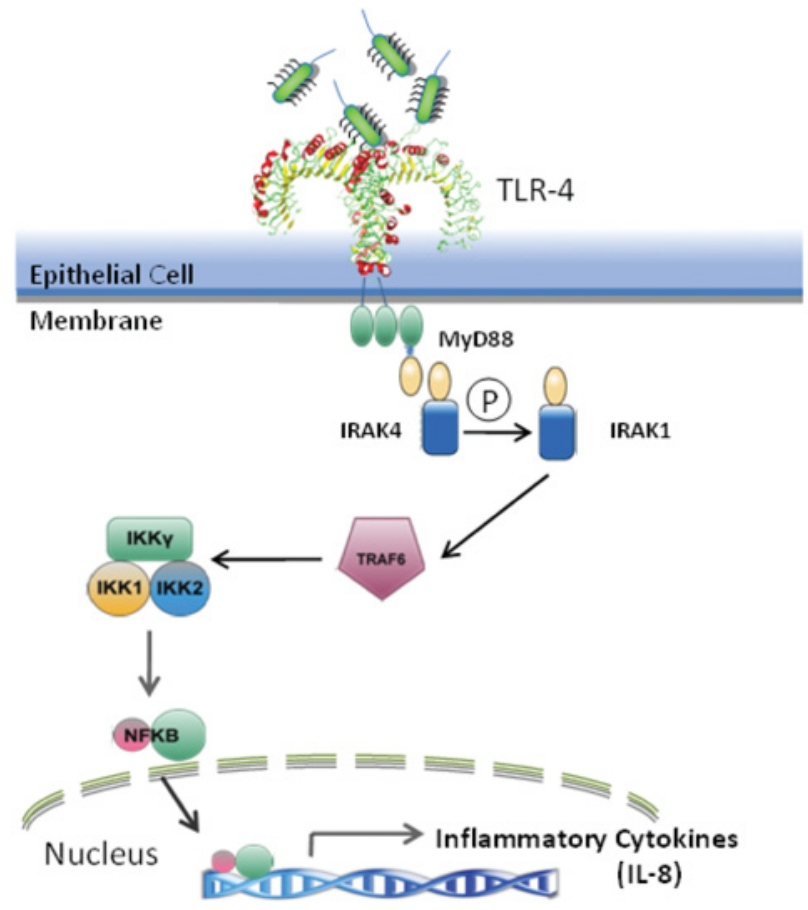

TIR domain

(P) Phosphorylation

Death domain

P. aeruginosa

(single-stranded RNA) and bacterial unmethylated CpG dinucleotide motifs respectively [30-35]. However, the most studied TLRs in CF are TLRs 2, 4 and 5. Heterodimerization of TLR2 with TLR1 or TLR6 results in the recognition of microbial components from the cell wall of Gram-positive bacteria, such as lipoproteins, peptidoglycan and lipoteichoic acid [36], whereas TLR4 is involved in the detection of LPS (lipopolysaccharide) and TLR5 with flagellin, which are both found in Gram-negative bacteria. LPS, which is found on Ps. aeruginosa, plays a major role in producing the chronic infection seen in the CF airways.

The binding of LPS results in TLR4 homodimerization, which subsequently causes recruitment of TIR-domaincontaining adaptor proteins such as MyD88 (myeloid differentiation factor 88). MyD88 then interacts with downstream signalling protein kinases through its death domain, allowing activation and phosphorylation of IRAK-4 (IL$1 \mathrm{R}$-associated kinase 4), which in turn activates TRAF-6 [TNF (tumour necrosis factor)-receptor-associated factor-6]. Ubiquitination of TRAF-6 and TAK-1 [TGF (transforming growth factor)- $\beta$-activated kinase] then occurs followed by the activation of IKK $[\mathrm{I} \kappa \mathrm{B}$ (inhibitor of $\mathrm{NF}-\kappa \mathrm{B}$ ) kinase] complex. This reverses its inhibiting function on NF- $\kappa \mathrm{B}$ and allows its subsequent translocation into the nucleus. $\mathrm{NF}-\kappa \mathrm{B}$ is one of the key regulating transcription factors of genes that are involved in inflammation and immunity
[32] (Figure 2). Activation of any TLR results in a Th1 innate immune response, which is characterized by $\mathrm{NF}-\kappa \mathrm{B}$ activation and the release of pro-inflammatory mediators. Cytokines and chemokines such as IL-8, TNF- $\alpha$ and IL-6 alert the immune system to the presence of infection [37], up-regulate antimicrobial peptides and increase phagocytosis of bacteria.

\section{Bacterial infection}

Infections by Gram-positive and Gram-negative bacteria aggravate the underlying mutations in the CFTR by exaggerating pro-inflammatory gene expression of cytokines such as IL-8, a potent chemoattractant of neutrophils. This recruitment of additional neutrophils to the airways results in further release of pro-inflammatory cytokines, constructing a cycle of inflammation. Initially throughout infancy and early childhood in CF patients, S. aureus and Haemophilus influenzae are the main infecting bacteria. It is thought that damage to the epithelial surface occurs as a result of $S$. aureus infection, helping to prime and increase attachment of Ps. aeruginosa [38,39]. However, more recent research suggests that continuous antistaphylococcal prophylaxis increases the rate of Ps. aeruginosa growth when compared with patients who receive no $S$. aureus antibiotic treatment [40]. Despite this, it is evident that by adulthood $80 \%$ of CF patients are chronically infected by $P$ s. aeruginosa, and this species correlates with a high mortality rate $[41,42]$. Current treatment of pulmonary infection in CF with antibiotic chemotherapy and chemoprophylaxis has increased patient life expectancy. However, this also provides a selective pressure causing bacteria such as Ps. aernginosa to undergo genetic modification. This allows the bacteria to gain traits such as antibiotic resistance [43] and biofilm formation. These biofilms are intricate bacterial communities, which are surrounded by a protective bacterial extracellular matrix, which reduces the rate of bacterial phagocytosis by immune cells [43]. Propagating Ps. aeruginosa within the biofilm is then released causing further inflammation and colonization.

\section{Lipid A modification}

Several genetic modifications such as antibiotic resistance and biofilm formation have been well researched; however, recently other less noticeable changes have been brought to the forefront. These types of changes are not regularly characterized in CF patients and, as a result, treatment efficiency may be reduced. One such adaptation is $P$. aeruginosa's ability to modify its LPS structure. LPS consists of three distinct structural elements: $\mathrm{O}$-antigen, core and lipid $\mathrm{A}$. The $\mathrm{O}$-antigen and the core are both composed of polysaccharides, whereas lipid A is composed of two central glucosamine dimers to which fatty acid chains, phosphates and amino sugars are attached [44]. It is a result of addition and/or extension of the fatty acid chains present in the lipid A component of LPS that helps Ps. aeruginosa convey resistance to CAMPs (cationic antimicrobial peptides) and produce a higher pro-inflammatory response $[45,46]$. By 
Figure 3 The lipid A structure of Ps. aeruginosa isolates from the environment (A), a CF patient with mild lung disease (B) and a CF patient with severe lung disease (C)

A

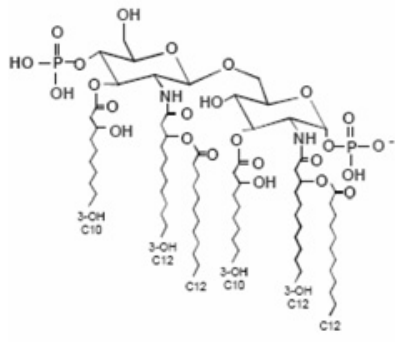

Environmental $m / z=1616$
B

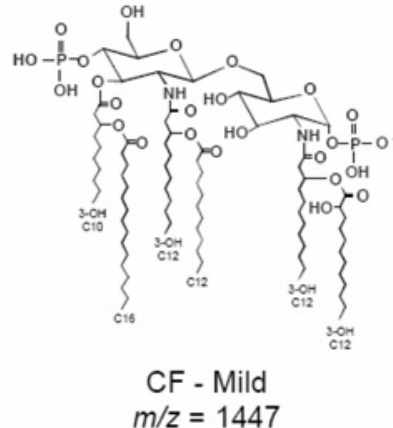

C

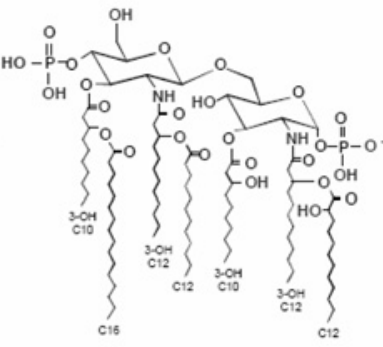

CF - Severe

$m / z=1855$ changing its isoelectric properties lipid A becomes less negatively charged, reducing the attractive forces to CAMPs. Initially $P$ s. aeruginosa lipid A contains two amide-linked fatty acids and two ester-linked fatty acids, producing a tetra-acylated structure [44-47]. The fatty acids attached in this structure vary in length from ten to twelve carbons and are hydroxylated at the 3-position. This base structure is modified further by the addition of two secondary fatty acids $\mathrm{C}_{12}$ and 2-OH $\mathrm{C}_{12}$. Analyses of LPS from $P$ s. aeruginosa isolates taken from $\mathrm{CF}$ patient airways have shown differential expression of fatty acid chains compared with isolates from acute infections or patients with broncheotisis. The general trend observed is the addition and lengthening of fatty acid chains over the duration of disease. For example, the lipid A structure (Figure 3A) of Ps. aeruginosa LPS isolated from the environment shows a hexa-acylated structure (six fatty acid chains) with all but one having a carbon chain length of 12 . Scrutinization of lipid A structure of Ps. aeruginosa LPS isolated from teenage CF patients with mild disease shows a hexa-acylated chain (six fatty acid chains, Figure 3B) with the new additional chain reaching a length of 16 carbons [48]. Finally, analysis of the lipid A structure of $P$ s. aernginosa LPS isolates from a subset of older CF patients with severe pulmonary disease produces a hepta-acylated structure (seven fatty acid chains, Figure 3C), which is thought of occur by loss of PagL deacylation activity [48]. Approx. $48 \%$ of isolates from CF patients with severe disease have a hepta-acylated structure and this is associated with an increased resistance to specific classes of antibiotics [49]. This intriguing association between disease severity and lipid A structure led us to our current investigations of the pro-inflammatory effect of these Ps. aeruginosa LPS isolates using CF and non-CF tracheal epithelial cells and IL-8 as a biomarker of inflammation. First results show that only CF epithelial cells respond with significant inflammation to some LPS isolates. The non-responsiveness of non-CF cells suggests a modified pathogen-host interaction as a significant virulent mechanism in pulmonary CF inflammation [46].

\section{Conclusion}

While the defects and modifications mentioned above contribute to the chronic infection and inflammation, which in turn results in mortality in CF patients, it is only a small part of the whole CF picture. Other cell types, for example macrophages and neutrophils, play critical roles in the cycle of inflammation. Often these cells produce more innately pro-inflammatory responses than epithelial cells. As well as the pro-inflammatory phenotype of the host, there is clear evidence that Ps. aeruginosa has developed mechanisms to avoid host defence and once established in CF lungs contributes significantly to the severity of disease. Ps. aeruginosa has shown to be resistant to numerous antibiotic treatments, which often encourage natural selection of modifications in Ps. aeruginosa. In this review, we have described the role of lipid $\mathrm{A}$ as a virulent factor of Ps. aeruginosa; however, it appears that further work is still needed to investigate the role of CFTR in the innate immune response and in modifying the pathogen-host interaction (e.g. TLRs). Moreover, counteracting genetic adaptation of Ps aernginosa would be beneficial to CF patients. Treatments that help remove additional fatty acid chains and aminoarbinose sugars, or prevent biofilm or mucoid phenotypes may help reduce inflammation and clear $P$ s. aeruginosa infection.

\section{Funding}

This work was supported by the Department of Employment and Learning Nothern Ireland, Cystic Fibrosis Trust [grant number PJ541] and a travel grant from the Biochemical Society.

\section{References}

1 Jacquot, J., Tabary, 0. and Clement, A. (2008) Hyperinflammation in airways of cystic fibrosis patients: what's new? Expert Rev. Mol. Diagn. 8, 359-363

2 Andersen, D. H. (1938) Cystic fibrosis of the pancreas and its relation to celiac disease: a clinical and pathologic study. Am. J. Dis. Child. 56, 344 
3 Riordan, J.R., Rommens, J.M., Kerem, B., Alon, N., Rozmahel, R., Grzelczak, Z., Zeilenski, J., Lok, S., Plavsic, N., Chou, J.L. et al. (1989) Identification of the cystic fibrosis gene: cloning and characterization of complementary DNA. Science $\mathbf{2 4 5}, \mathbf{1 0 6 6 - 1 0 7 3}$

4 Andersen, D.H. and Hodges, R. (1946) Celiac syndrome v. genetics of cystic fibrosis of the pancreas with a consideration of etiology. Am. J. Dis. Child. 72, 62

5 Trezise, A.E., Chambers, J.A., Wardle, C.)., Gould, S. and Harris, A. (1993) Expression of the cystic fibrosis gene in human foetal tissues. Hum. Mol. Genet. 2, 213-218

6 Kartner, N., Augustinas, 0., Jensen, T.J., Naismith, A.L. and Riordan, J.R. (1992) Mislocalization of $\Delta$ F508 CFTR in cystic fibrosis sweat gland. Nat. Genet. 1, 321-327

7 Yang, Y., Raper, S.E., Cohn, J.A., Engelhardt, J.F. and Wilson, J.M. (1993) An approach for treating the hepatobiliary disease of cystic fibrosis by somatic gene transfer. Proc. Natl. Acad. Sci. U.S.A. 90, 4601-4605

8 Ratjen, F. and Döring, G. (2003) Cystic fibrosis. Lancet 361, 681-689

9 Pier, G.B. (2002) CFTR mutations and host susceptibility to Pseudomonos aeruginosa lung infection. Curr. Opin. Microbiol. 5, 81-86

10 Nissim-Rafinia, M., Linde, L. and Kerem, B. (2006) The CFTR gene: structure, mutations and specific therapeutic approaches. Prog. Respir. Res. 34, 2-10

11 Sheppard, D.N. and Welsh, M.J. (1999) Structure and function of the CFTR chloride channel. Physiol. Rev. 79, S23-\$45

12 Reference deleted

13 Kerem, B., Rommens, J.M., Buchanan, J.A., Markiewicz, D., Cox, T.K., Chakravarti, A., Buchwald, M. and Tsui, L.C. (1989) Identification of the cystic fibrosis gene: genetic analysis. Science $\mathbf{2 4 5}$, 1073-1080

14 Du, K., Sharma, M. and Lukacs, G.L. (2005) The $\Delta$ F508 cystic fibrosis mutation impairs domain-domain interactions and arrests post-translational folding of CFTR. Nat. Struct. Mol. Biol. 12, 17-25

15 Rowe, S.M., Miller, S. and Sorscher, E.J. (2005) Cystic fibrosis. N. Engl. J. Med. 352, 1992-2001

16 Rubenstein, R.C. (2005) Novel, mechanism-based therapies for cystic fibrosis. Curr. Opin. Pediatr. 17, 385-392

17 Shoshani, T., Augarten, A., Gazit, E., Bashan, N., Yahav, Y., Rivlin, Y., Tal, A., Seret, H., Yaar, L., Kerem, E. et al. (1992) Association of a nonsense mutation (W1282X), the most common mutation in the Ashkenazi Jewish cystic fibrosis patients in Israel, with presentation of severe disease. Am. J. Hum. Genet. 50, 222-228

18 The Cystic Fibrosis Genotype-Phenotype Consortium (1993) Correlation between genotype and phenotype in patients with cystic fibrosis. N. Engl. J. Med. 329, 1308-1313

19 Knowles, M.R. and Boucher, R.C. (2002) Mucus clearance as a primary innate defense mechanism for mammalian airways. J. Clin. Invest. 109 571-577

20 Wanner, A., Salathé, M. and O'Riordan, T.G. (1996) Mucociliary clearance in the airways. Am. J. Respir. Crit. Care Med. 154, 1868-1902

21 Matsui, H., Grubb, B.R., Tarran, R., Randell, S.H., Gatzy, J.T., Davis, C.W. and Boucher, R.C. (1998) Evidence for periciliary liquid layer depletion, not abnormal ion composition, in the pathogenesis of cystic fibrosis airways disease. Cell 95, 1005-1015

22 Mall, M., Grubb, B.R., Harkema, J.R., O'Neal, W.K. and Boucher, R.C. (2004) Increased airway epithelial $\mathrm{Na}^{+}$absorption produces cystic fibrosis-like lung disease in mice. Nat. Med. 10, 487-493

23 Tarran, R., Grubb, B.R., Gatzy, J.T., Davis, C.W. and Boucher, R.C. (2001) The relative roles of passive surface forces and active ion transport in the modulation of airway surface liquid volume and composition. J. Gen. Physiol. 118, 223-236

24 Matsui, H., Davis, C.W., Tarran, R. and Boucher, R.C. (2000) Osmotic water permeabilities of cultured, well-differentiated normal and cystic fibrosis airway epithelia. J. Clin. Invest. 105, 1419-1427

25 Medzhitov, R. and Janeway, Jr, C. (2000) The Toll receptor family and microbial recognition. Trends Microbiol. 8, 452-456

26 Aderem, A. and Ulevitch, R.J. (2000) Toll-like receptors in the induction of the innate immune response. Nature $\mathbf{4 0 6}, 782-787$

27 Hornef, M.W. and Bogdan, C. (2005) The role of epithelial Toll-like receptor expression in host defense and microbial tolerance. J. Endotoxin Res. 11, 124-128
28 Lemaitre, B., Nicolas, E., Michaut, L., Reichhart, J.M. and Hoffmann, J.A. (1996) The dorsoventral regulatory gene cassette spotzle/Toll/coctus controls the potent antifungal response in Drosophilo adults. Cell 86, 973-983

29 Gay, N.J. and Keith, F.J. (1991) Drosophila Toll and IL-1 receptor. Nature 351, 355-356

30 Akira, S., Uematsu, S. and Takeuchi, 0. (2006) Pathogen recognition and innate immunity. Cell 124, 783-801

31 Medzhitov, R., Preston-Hurlburt, P. and Janeway, Jr, C.A. (1997) A human homologue of the Drosophila Toll protein signals activation of adaptive immunity. Nature 388, 394-397

32 Creagh, E.M. and O'Neill, L.A. (2006) TLRs, NLRs and RLRs: a trinity of pathogen sensors that co-operate in innate immunity. Trends Immunol. 27, 352-357

33 O'Neill, L.A. (2002) Signal transduction pathways activated by the IL-1 receptor/Toll-like receptor superfamily. Curr. Top. Microbiol. Immunol. 270, 47-61

34 Fritz, J.H. and Girardin, S.E. (2005) How Toll-like receptors and nod-like receptors contribute to innate immunity in mammals. J. Endotoxin Res. 11, 390-394

35 Takeda, K., Kaisho, T. and Akira, S. (2003) Toll-like receptors. Annu. Rev. Immunol. 21, 335-376

36 Wetzler, L.M. (2003) The role of Toll-like receptor 2 in microbial disease and immunity. Vaccine $\mathbf{2 1}$ (Suppl. 2), S55-S60

37 Aderem, A. and Underhill, D.M. (1999) Mechanisms of phagocytosis in macrophages. Annu. Rev. Immunol. 17, 593-623

38 Govan, J.R. and Nelson, J.W. (1992) Microbiology of lung infection in cystic fibrosis. Br. Med. Bull. 48, 912-930

39 Stutman, H.R., Lieberman, J.M., Nussbaum, E. and Marks, M.I. (2002) Antibiotic prophylaxis in infants and young children with cystic fibrosis: a randomized controlled trial. J. Pediatr. 140, 299-305

40 Ratjen, F., Comes, G., Paul, K., Posselt, H.G., Wagner, T.O. and Harms, K. (2001) Effect of continuous antistaphylococcal therapy on the rate of $P$. aeruginoso acquisition in patients with cystic fibrosis. Pediatr. Pulmonol. 31, $13-16$

41 Cystic Fibrosis Foundation (2008) Patient Registry Annual Data Report 2007, Cystic Fibrosis Foundation, Bethesda, http://www.cff.org/ UploadedFiles/research/ClinicalResearch/2007-Patient-RegistryReport.pdf

42 Accurso, F.J. (2007) Update on cystic fibrosis 2006. Am. J. Respir. Crit. Care Med. 175, 754-757

43 Meluleni, G.J., Grout, M., Evans, D.J. and Pier, G.B. (1995) Mucoid Pseudomonas aeruginosa growing in a biofilm in vitro are killed by opsonic antibodies to the mucoid exopolysaccharide capsule but not by antibodies produced during chronic lung infection in cystic fibrosis patients. J. Immunol. 155, 2029-2038

44 Raetz, C.R. and Whitfield, C. (2002) Lipopolysaccharide endotoxins. Annu. Rev. Biochem. 71, 635-700

45 Ernst, R.K., Yi, E.C., Guo, L., Lim, K.B., Burns, J.L., Hackett, M. and Miller, S.I. (1999) Specific lipopolysaccharide found in cystic fibrosis airway Pseudomonos aeruginoso. Science 286, 1561-1565

46 Buchanan, P.J., Ernst, R.K., Elborn, J.S. and Schock, B. (2008) Response to Pseudomonas aeruginosa in cystic fibrosis depends on lipid A structure of LPS. Ir. J. Med. Sci. 177, s456

47 Kulshin, V.A., Zahringer, U., Lindner, B., Jager, K.E., Dmitriev, B.A. and Rietschel, E.T. (1991) Structural characterization of the lipid A component of Pseudomonos aeruginoso wild-type and rough mutant lipopolysaccharides. Eur. J. Biochem. 198, 697-704

48 Ernst, R.K., Hajjar, A.M., Tsai, J.H., Moskowitz, S.M., Wilson, C.B. and Miller, S.I. (2003) Pseudomonas aeruginosa lipid A diversity and its recognition by Toll-like receptor 4. J. Endotoxin Res. 9, 395-400

49 Ernst, R.K., Moskowitz, S.M., Emerson, J.C., Kraig, G.M., Adams, K.N., Harvey, M.D., Ramsay, B., Speert, D.P., Burns. J.L., and Miller, S.I. (2007) Unique lipid A modifications in Pseudomonos aeruginoso isolated from the airways of patients with cystic fibrosis. J. Infect. Dis. 196, 1088-1092

Received 4 March 2009

doi:10.1042/BST0370863 